\title{
O ensino da matemática na educação infantil indígena Kaingang no Paraná
}

\author{
Mathematics teaching for the Kaingang in indigenous kindergarten \\ education of Paraná
}

\author{
Luciana Regina Andrioli ${ }^{1}$ \\ Adriana Silva Oliveira ${ }^{2}$
}

\begin{abstract}
RESUMO
O texto apresenta uma discussão acerca do ensino de Matemática e a educação infantil indígena Kaingang no Paraná, destacando o papel da Matemática a partir dos pressupostos da Teoria Histórico-Cultural, com o objetivo de refletir sobre as possibilidades de desenvolvimento e processo do ensino e aprendizagem significativos. Por meio de pesquisa bibliográfica e empírica, foi possível perceber que os estudos são incipientes sobre a temática proposta, apesar de ser um tema relevante. Destacamos a organização do ensino de Matemática na educação infantil indígena como um componente curricular imprescindível, pois os conhecimentos matemáticos favorecem o desenvolvimento e a aprendizagem das crianças Kaingang, bem como possibilitam o melhor desempenho dos indígenas na sociedade que estão inseridos, com as lutas e conquistas relacionadas à terra e garantias legais.
\end{abstract}

Palavras-chave: Educação infantil indígena. Ensino da Matemática. Crianças Kaingang. Aprendizagem.

\begin{abstract}
This paper discusses Mathematics teaching for the Kaingang and indigenous kindergarten education in Paraná, Brazil. The role played by Mathematics is highlighted based on CulturalHistorical theory. The aim is to reason about meaningful possibilities of development as well as teaching and learning processes. Empirical and literature-review research led researchers to apprehend that studies on this theme are yet elementary, despite the latter being relevant. We highlight that arrangements for Mathematics teaching in indigenous kindergarten education is an essential component of curricula. This is because knowledge in Mathematics favors Kaingang children's development and learning. Additionally, it allows for indigenous people to better act in the society they are part of, especially with regards to land and legal guarantees-related fights and occupation.
\end{abstract}

Keywords: Indigenous kindergarten education. Mathematics teaching. Kaingang children. Learning.

${ }_{1}^{1}$ Doutora em Educação pela Universidade Estadual de Maringá (UEM), supervisora escolar na Prefeitura de Maringá- Paraná. Orcid: https://orcid.org/0000-0003-3399-9095. E-mail: lureandrioli@gmail.com.

2 Mestre em Educação pela Universidade Estadual de Maringá (UEM), professora colaboradora na Universidade Estadual de Maringá, e na Universidade Estadual do Paraná - UNESPAR- campus de Paranavaí. Orcid: https://orcid.org/0000-0001-6024-3205. E-mail: adriana.eira@gmail.com. 


\section{Introdução}

Durante séculos, a educação escolar indígena teve caráter disciplinador, cuja finalidade era o abandono da cultura e a integração dos grupos étnicos à sociedade nacional. Atualmente, essa política modificada nos anos 1990, reconhece a diversidade cultural nos documentos oficiais (Constituição Federal, 1988; Lei de Diretrizes e Bases da Educação Nacional - LDB, 1996; Referencial Curricular Nacional para as Escolas Indígenas, 1998) e nas discussões teóricas, as quais defendem a valorização dos conhecimentos tradicionais de cada povo indígena, a utilização de suas línguas maternas e processos próprios de aprendizagem.

A educação escolar indígena está presente nas Terras Indígenas (TI), cada povo, cada Terra Indígena, com sua comunidade, tem uma relação própria com a escola e com a participação dos povos indígenas na sua formulação e gestão, embora encontre entraves junto às diferentes instâncias do poder público, composto de um sistema de ensino que visa à padronização (FAUSTINO 2006; ANDRIOLI, 2012; MENEZES, 2016).

Segundo o último recenseamento, são 305 povos e cerca de 180 línguas, além das variações e parcialidades linguísticas (BRASIL, 2010). Dados do Censo Escolar da Educação Básica 2016 (BRASIL, 2017) indicam a existência de 3.115 escolas indígenas no Brasil, o que caracteriza um aumento no número de escolas, comparando os dados censitários anteriores: 2.323 em 2005 e 3.085 em 2015 (ANDRIOLI, 2019).

Destacamos a expansão da educação infantil que, nos últimos oito anos, apresentou um crescimento de 56,9\% no número de escolas que oferecem creche, totalizando 64,5 mil creches no Brasil, sendo que 295 estão localizadas em Terras Indígenas (INEP, 2017). Dados do Observatório do PNE apresentam que, no Brasil, foram 28.506 matrículas em 1.675 estabelecimentos de educação indígena na educação infantil. No Paraná, a educação infantil está presente nas 39 escolas indígenas, evidenciando o fato de que as famílias enviam seus filhos, desde a mais tenra idade, à escola (ANDRIOLI; FAUSTINO, 2019).

Em relação à educação infantil indígena, estudos e reflexões realizadas no âmbito dos projetos de ensino e extensão na área da educação escolar indígena da 
Universidade Estadual de Maringá apontaram alguns princípios teóricos metodológicos da abordagem histórico-cultural que orientam o processo de ensino e aprendizagem de Matemática na educação infantil. Destes, destacamos: a mobilização do interesse das crianças pelos conteúdos a serem ensinados; a organização e utilização de recursos diferenciados e materiais didáticos para trabalhar o entendimento e elaboração dos conceitos nos discentes; o desenvolvimento de atividades lúdicas como forma de suscitar o empenho das crianças; a importância do professor estar em atividade no planejamento, compreendendo a historicidade da elaboração do conceito científico a ser ensinado e, assim, poder atuar com o desenvolvimento do pensamento teórico em situações de ensino.

Princípios estes que nos mobilizam a refletir sobre o ensino de Matemática para a criança indígena que, no caso de uma criança Kaingang, ora frequenta a escola da comunidade em sua Terra Indígena, ora vivencia experiências matemáticas com seus familiares, participando ativamente do cotidiano cultural étnico, quando, por exemplo, acompanha a venda de artesanato na cidade. Assim, debater sobre educação infantil indígena envolve valores individuais e sociais, necessitando avaliar as necessidades e experiências apropriadas para crianças e adultos.

Um dos aspectos importantes da Teoria Histórico-Cultural refere-se à compreensão do papel do ensino escolar. A escola para a infância desempenha um papel primordial na aprendizagem e desenvolvimento das crianças, deve possuir organização de tempo e espaços significativos, que possibilite o desenvolvimento infantil, onde as crianças possam aprender a ler, escrever, contar, se reunir para brincar, interagir, estabelecer relações sociais e que também possam vivenciar a cultura desenvolvida e acumulada social e historicamente pela humanidade.

Levando em consideração as informações supracitadas sobre como a educação infantil acontece nas escolas indígenas, neste artigo, apresentaremos o ensino de Matemática na educação básica indígena. O texto está organizado levando em consideração dois aspectos: no primeiro, apresentaremos a educação infantil indígena com base nos autores que discutem essa temática, objetivando compreender a realidade da educação infantil indígena Kaingang; no segundo, a importância do ensino de Matemática para a educação escolar indígena como 
disciplina que potencializa o desenvolvimento de funções psíquicas superiores, como a percepção, abstração, memória e criatividade.

\section{A educação infantil indígena: alguns apontamentos}

A educação infantil indígena é uma realidade nas Terras Indígenas. No estado do Paraná, é comum as famílias indígenas Kaingang enviarem seus filhos à escola. Entretanto, conforme explana Andrioli (2019), a educação infantil indígena é um tema de discussão recente no Brasil, fato evidenciado pela escassez de publicações sobre o tema no país. Até então, as únicas publicações disponíveis eram: Rosemberg (2005), Coelho (2006), Tiriba (2011), Nascimento, Brand e Aguilera Urquiza (2006), Vieira (2012), Rossato (2014), Silva e Mota (2014), Cruz (2016), Machado (2016) e Troquez (2016).

A publicação “Discutindo Políticas de Educação Infantil e Educação Escolar Indígena" do Movimento Interfóruns de Educação Infantil do Brasil (MIEIB) ressalta a incipiência dos debates sobre o tema. A publicação objetiva a síntese das discussões e posições sobre a educação infantil indígena, pois é um assunto complexo, com muitas determinantes e variáveis. Assim, os estudos são incipientes e há pouco tempo que se apresentam como questão para reflexão. Robemberg (2005) destaca a iniciativa pioneira desse movimento, o MIEIB, para a temática, e que até o momento eram abordadas separadamente: educação infantil e educação escolar indígena. A educação infantil indígena está ganhando relevância na agenda das políticas educacionais, mas os estudos específicos sobre o tema no Brasil são escassos e há pouco interesse da área.

Para o MIEIB, Coelho (2006) aponta que é preciso debater e estudar as questões que afetam a temática imediatamente para problematizar as especificidades da educação infantil ofertada às crianças indígenas residentes em comunidades indígenas ou centros urbanos, pois verificou que as definições e orientações da política nacional de educação infantil não abordam as especificidades das crianças indígenas e as definições e orientações da política de educação escolar indígena não contemplam a educação infantil.

A autora destaca que, no âmbito das políticas afirmativas e do aumento das 
discussões e reflexões sobre a educação escolar indígena, a especificidade da educação da criança de até seis anos não vem sendo completada. Desta forma,

[...] o direito constitucional de todas as crianças brasileiras de até seis anos de idade à educação escolar precisa ser discutido, explicitado, compreendido e principalmente incluído na política educacional referente aos povos indígenas. Como o Estado deve cumprir seu papel frente o direito das crianças indígenas à educação infantil? Existem outras possibilidades de atendimento que não a oferta organizada em creches e pré-escolas? Como garantir que a criança indígena residente em zona urbana, matriculada em instituições públicas ou privadas de educação infantil, tenha respeitado o direito a etnia, crenças e valores diferentes? (COELHO, 2006, p.6).

Para pensar essas questões é preciso o diálogo que abranja “[...] as representações dos povos indígenas, os gestores da política educacional, as entidades de professores, organizações não governamentais e os movimentos de defesa da educação" (COELHO, 2006, p.7), pois as orientações da política educacional para a educação escolar indígena (Constituição Federal; LDBN; RCNEI) não contemplam a educação infantil indígena.

O formato institucional da educação infantil que conhecemos é resultado das sociedades europeias urbanas, pois foi organizado para atender às necessidades/interesses das sociedades europeias modernas e daquelas que seguem este modelo. Contudo, além das questões associadas às necessidades/demandas das famílias, observam-se o movimento de ampliação da educação infantil voltado não aos interesses das crianças e sua família, não centradas nas necessidades de cuidar/educar, mas para inculcar ideológica e culturalmente a formação de um "novo" cidadão e uma maternidade sadia, bem como combater à fome ou pobreza, ampliar e defender o mercado de trabalho e postos de liderança política, sindical e profissional de certos grupos ou pessoas; e razões eleitorais/“marqueteiras” (ROSEMBERG, 2005).

Nascimento, Brand e Urquiza (2006) destacam que instituições voltadas para o atendimento às crianças antes da idade escolar foram fundadas pela sociedade burguesa, no âmbito da urbanização e da industrialização, com o intuito de educar e disciplinar a criança nos novos padrões sociais dominantes, principalmente, de um 
novo tempo, voltado para o tempo do trabalho e da produção.

Todavia, o tempo da criança é o tempo do não-trabalho e o da criança indígena está relacionado às questões simbólicas que a localiza e a insere no mundo social (NUNES, 2002 apud NASCIMENTO; BRAND; URQUIZA, 2006). Visto que a "estrutura temporal" do cotidiano de uma criança indígena possui outra complexidade, "[...] que não aquela do espaço escolar, com seus tempos prédeterminados e constantemente dirigidos, exigindo outras correlações" (NASCIMENTO; BRAND; URQUIZA, 2006, p.2).

Conforme Tiriba (2011), embora alguns povos indígenas reivindiquem a educação infantil em um cenário político de afirmação da identidade e dos direitos dos indígenas brasileiros, é preciso indagar

[...] o que significa, para as crianças pequenas afastarem-se dos adultos e do contexto de sua grande família tribal para estarem, cotidianamente, em creches e pré-escolas? Em que medida as IEI contribuem para a afirmação da identidade sócio ambiental e cultural das crianças e de seus povos de origem? (TIRIBA, 2011, p.34).

Os debates sobre educação infantil envolvem os valores individuais e sociais e se avaliam as necessidades e experiências apropriadas para crianças e adultos, isto é, uma proposta educacional, de socialização, de cuidado, é norteada por princípios do que seja desejável em oposição ao que é tido como indesejável naquela cultura/sociedade. Neste sentido, há grande variação social e histórica dos valores educacionais em qualquer etapa da vida, a qual é mais intensa quanto menor a criança, pois nas sociedades contemporâneas, a criança é entendida como um ser moldado (ROSEMBERG, 2005).

As políticas, programas e projetos voltados para a educação infantil, especialmente à criança pequena pobre, resultam de modelos hegemônicos, preferencialmente de baixo custo, introduzidos nos países em desenvolvimento, diminuindo a opção familiar de participar ou não de programa de educação infantil, bem como apresentam os valores sobre como ser uma boa mãe/ bom pai e um ambiente educacional para a criança. Esses modelos diminuem as chances de escolha das famílias, pois não possibilitam a expressão de seus valores. Assim, 
“[...] de que instrumentos dispomos para apreender a demanda das famílias por tipo de serviço de educação infantil? Entre os povos indígenas, que demandas privilegiam?" (ROSEMBERG, 2005, p.7).

As reflexões de Rosemberg (2005) possibilitam muitos questionamentos sobre a temática: a proposta de educação infantil indígena deve acontecer a partir de uma consulta e de debate local, refletindo sobre motivações e meios, bem como com a participação de professores indígenas que falem a língua local e pratiquem usos e costumes locais de socializações primária e secundária.

Nascimento, Brand e Urquiza (2006) também destacam que é preciso pensar sobre a idade de ingresso das crianças no processo de escolarização, bem como as indagações sobre os efeitos da iniciativa na constituição da identidade indígena, da organização sociocultural e da socialização primária (NASCIMENTO; BRAND; URQUIZA, 2006).

Educação infantil em terras indígenas não pode ser subterfugio, um meio para redução da desnutrição e taxas de mortalidade (programas de emergência), mas é necessário que "[...] reflexões, debates e propostas devem ser diferenciadas para população indígena urbana e/ou comunidades urbanizadas" (ROSEMBERG, 2005, p.10), bem como poderá ser diferenciada, pois “[...] o modelo de socialização/educação/cuidado assentado na família nuclear me parece intrínseco à EI enquanto instituição" (idem, p.10).

No atual contexto educacional, é preciso refletir sobre a necessidade do respeito e do pluralismo cultural, desde o ensino infantil, de forma que as pessoas reflitam sobre as diferenças e tenham percepções de ver, conviver e respeitar as especificidades de cada um e o meio social em que estão inseridas (CRUZ, 2016).

Atualmente, políticas, programas e projetos de educação infantil se desenvolvem na conjuntura econômica mundial globalizada. Nota-se que os países enfrentam os desafios das políticas de ajuste consequentes ao novo ordenamento econômico mundial: com redução dos gastos sociais, flexibilização dos contratos de trabalho e enfraquecimento dos espaços tradicionais de debate político (e sua substituição pelos meios de comunicação de massa), entre outras provações. Tais fatos limitam o poder de participação e tomada de consciência sobre a própria 
realidade (ROSEMBERG, 2005).

Desta forma, é preciso refletir sobre as políticas voltadas para a educação infantil indígena e às práticas pedagógicas nas escolas, para que o trabalho pedagógico dirigido às crianças indígenas não reproduza apenas as práticas maternais, assistencialismo, cuidados, a precariedade de condições de trabalho das professoras, da estrutura, dos recursos, mas que possibilite o desenvolvimento das crianças, práticas educativas plenas de aprendizagem, com atividades lúdicas, jogos, brincadeiras (ROSEMBERG, 2005), respeitando os processos próprios de ensino e aprendizagem e neste ponto que destacamos a importância do ensino da matemática nas práticas da educação infantil Kaingang.

\section{0 ensino da matemática na educação infantil indígena Kaingang}

O Referencial Curricular Nacional da Educação Indígena (RCNEI), um referencial específico para a educação escolar indígena, não faz menção a educação infantil, mas apresenta o ensino de Matemática nas escolas indígenas. Esse ponto que iremos destacar: o papel do ensino da matemática na educação infantil indígena, tomamos como base a pesquisa empírica com o povo Kaingang para suscitar algumas reflexões sobre a Matemática na escola indígena no Paraná.

O RCNEI (BRASIL, 1998) argumenta ser uma disciplina fundamental para que a criança indígena adquira o entendimento do mundo do não-indígena, conhecimento reconhecido pelos indígenas como fundamental para a autossustentação das comunidades e autonomia com a sociedade envolvente. $\mathrm{O}$ documento afirma que:

[...] Saber matemática é um pré-requisito para o desenvolvimento de atividades administrativas, de proteção ambiental e territorial, e de atenção à saúde, entre outras. Reivindicar a posse do território imemorial e vigiar as fronteiras, por exemplo, exige a compreensão de aspectos cartográficos, como escala e área. Operar rádio transmissor também requer cumprir horários rígidos e sintonizar frequências. Administrar o posto de saúde local ou entender como administrar medicamentos contra malária, tuberculose ou mesmo gripe, envolve a compra de remédios, verificação de datas de validade, prescrição e medição de quantidades específicas de 
medicamentos. Índios contratados pela Funai, prefeituras ou secretarias locais, manipulam contracheques e extratos bancários. Lidar com dinheiro é ainda uma preocupação constante para todos aqueles que comercializam produtos na região ou exportam para outros países (BRASIL, 1998, p.160).

A educação matemática está presente na infância indígena. As crianças indígenas estão em contato com a Matemática desde a tenra idade, estão em uma sociedade com números, formas e grandezas, pois elas possuem um comportamento comum, "[...] a sua onipresença na aldeia, a sua liberdade de acesso a tudo e a todos, e a possibilidade de olharem e participarem em tudo o que acontece à sua volta [...]” (NUNES, 2003, p.34). Para Alvares (2004), as comunidades indígenas permitem a circulação e a penetração das crianças em todas as dimensões, e estas transitam entre as diversas categorias sociais, vivenciam a composição e os papeis sociais do grupo, são ativas junto aos adultos no cotidiano e, assim, se apropriam do universo social, aprendem, constroem juntos as relações sociais e a dinâmica da vida social e política do grupo, sempre orientados pelos mais velhos ou adultos (ANDRIOLI; FAUSTINO, 2019).

$\mathrm{Na}$ aldeia, as crianças Kaingang estão presentes nos mais diversos espaços da comunidade: trilhas, rios, matas, campo de futebol, escola e em atividades como celebrações, cultos, missas, festas, recepção das visitas, velórios e acompanham os pais nas atividades de trabalho, como artesanato e roças. É nesse processo de vivência que se dá grande parte da aquisição de suas aprendizagens e desenvolvimento. Ainda que brinquem mais em seu grupo familiar, as crianças "[...] parecem ser as únicas na aldeia que têm o direito de estar em todo lugar, participar de quase todos os acontecimentos sociais [...]" (FAUSTINO, 2010, p. 207).

Como as crianças vivenciam todas as atividades familiares, destacamos que quando estão na cidade vendendo o artesanato, uma forma de sobreviverem, de luta e resistência, as crianças vendem o artesanato produzido pela família, nesse processo aprendem a Matemática, por exemplo, quando contam o dinheiro que ganham. Assim, as crianças indígenas Kaingang já participam da vida econômica da família (ANDRIOLI, 2019). A criança deve participar da economia familiar, saber onde os pais trabalham, em que consiste o trabalho dos pais, as dificuldades 
e êxitos, compreender que o dinheiro que os pais ganham, “[...] não é somente um cômodo elemento aquisitivo, mas fruto de um trabalho social intenso e útil [...]”, conforme cita Makarenko (1981, p.69).

Quando as crianças indígenas Kaingang, após a venda dos artesanatos, retornam à Terra Indígena, possuem conhecimentos matemáticos, pois participam da vida econômica da família. Neste sentido, o RCNEI (1998) destaca que a Matemática envolvida nas práticas do cotidiano pode beneficiar o planejamento, a pesquisa e o gerenciamento de sua atividade produtiva, como a comercialização do artesanato.

A educação matemática está presente na educação infantil, fato observado nas práticas pedagógicas de uma escola indígena no Paraná. ${ }^{3} \mathrm{Na}$ educação infantil, atuam professores indígenas, falantes da língua Kaingang e professores não indígenas. O currículo segue conforme as orientações da Secretaria de Estado da Educação do Paraná, sendo adaptado pelos professores, conforme a realidade de cada turma. As atividades pedagógicas são compostas de brincadeiras, passeios, contação de histórias, atividades com alfabeto, músicas e jogos. As crianças realizam o que seus professores propõem dentro de seus próprios ritmos e vontades. Entretanto, os professores buscam seguir o que foi planejado (ANDRIOLI, 2019; ANDRIOLI; FAUSTINO, 2019).

A Proposta Pedagógica Curricular da Educação Infantil (2016) está organizada em sete eixos que norteiam o trabalho pedagógico na instituição de ensino, considerando a relevância das interações e brincadeiras no processo educativo dos alunos, são eles: EIXO I - Identidade e autonomia; EIXO II - Movimento; EIXO III Linguagem verbal e não verbal; EIXO IV - Arte; EIXO V - Matemática; EIXO VI Natureza e sociedade; EIXO VII - Kaingang: Língua materna.

Neste sentido, a PPC (2016) destaca que o documento é mais um subsídio para o trabalho docente, podendo ser utilizado como referencial, tanto para o planejamento das aulas, quanto para o acompanhamento do trabalho pedagógico.

A organização por eixos compreende conhecimentos e seus respectivos conteúdos a serem desenvolvidos pelos professores e apreendidos pelos alunos. No

\footnotetext{
3 Tese de doutorado em Educação. Projeto aprovado pelo CONEP - Número do Parecer: 2.677.272/ Aprovado pela FUNAI - Ofício n ${ }^{\circ}$ 289/2018/AAEP-FUNAI.
} 
eixo Matemática, a PPC (2016) destaca que a criança, desde o nascimento, está em contato de forma intencional com os números, quando, por exemplo, mostra com os dedos a idade, brinca com o telefone, dentre outras práticas. Assim,

[...] a construção de noções matemáticas faz parte da vida da criança, por meio de sua relação com o meio participa de diversas situações que envolvem números, contagem, classificação, seriação, deslocamento, entre outras. O trabalho com noções matemáticas deve promover que as crianças possam expor suas ideias, fazer comparações, perguntas, escutar o outro, possibilitando que estruturem, ampliem e modifiquem seus conhecimentos prévios, e adquiram novos conhecimentos (PROPOSTA PEDAGÓGICA CURRICULAR DA EDUCAÇÃO INFANTIL, 2016, p.48).

A noção e o campo matemático (espaço e forma, número e sistema de numeração, grandezas e medidas, tratamento da informação) implicam o trabalho com os seguintes conceitos matemáticos:

- tamanho - lugar - distância - forma, bidimensionalidade e tridimensionalidade;

- $\quad$ quantidade - contagem oral - notação numérica e/ou registros não convencionais - ideias de juntar, tirar, colocar, comparar, repartir e distribuir - agrupamento - relação entre quantidades capacidade - tempo;

- $\quad$ posição - medição - direção;

- $\quad$ volume - comprimento - massa - peso - utilização de unidades convencionais e não convencionais.

- tratamento da informação: Gráficos e tabelas; Gráficos pictóricos. (PROPOSTA PEDAGÓGICA CURRICULAR DA EDUCAÇÃO INFANTIL, 2016, p.48).

Esses conceitos matemáticos devem ser trabalhados por meio do manuseio de blocos lógicos, de forma a identificar, separar e agrupar as peças por cores, formas, tamanhos e espessuras e também com a utilização dos jogos simbólicos. Outra forma seria em meio às brincadeiras, nas quais os educadores agrupam objetos que combinam e solicitam que os educandos os classifiquem (PPC, 2016). Assim,

A utilização de jogos de memória e quebra-cabeças pode ser usada como estratégia para promover situações problemas em que as crianças necessitem explorar seu raciocínio lógico para solucionálos. Os planos de trabalho que envolvem desenho, colagem, contorno e recorte de diferentes formas também auxiliam nessa aprendizagem, assim como a utilização de diversos materiais, 
tais como: massa de modelar, argila, pedras e blocos geométricos das mais diversas formas e espessuras, volumes e tamanhos (PROPOSTA PEDAGÓGICA CURRICULAR DA EDUCAÇÃO INFANTIL, 2016, p.49).

Kalmykova (1977) destaca que a formação dos conceitos depende da diversidade de materiais, pois, quanto mais variados, mais fácil e correto será o processo de abstração. Entretanto,

[...] não pode haver uma experiência sensorial de todos os objectos, e têm que se adotar métodos que dêem às crianças capacidades para ampliarem o conceito que estão a estudar. Os materiais deveriam ser apresentados e usados de modo a que as suas características não essenciais variassem já que este facto ajuda a pôr em relevo as características fundamentais e essenciais: deve haver uma formulação verbal do essencial e do não essencial, e têm que se pôr especialmente em relevo os traços essenciais do conceito [...] (KALMYKOVA, 1977, p.13).

O uso do calendário possibilita que as crianças percebam a sucessão de acontecimentos e a passagem do tempo, relacionando com a sequência numérica e estabelecendo relações entre o ontem, hoje, amanhã, agora, entre outros (PPC, 2016). Desta forma, é preciso o trabalho com a ludicidade, sem que ocorra a mecanização, é necessário que compreendam o que estão fazendo, realizando, por isso, cabe ao professor desenvolver

[...] projetos que abordem a contagem oral por meio de cantigas de roda, parlendas, contos, brincadeiras e jogos, como, por exemplo, do folclore brasileiro que é constituído por uma fonte riquíssima de cantigas e rimas infantis envolvendo contagens e números (PROPOSTA PEDAGÓGICA CURRICULAR DA EDUCAÇÃO INFANTIL, 2016, p.49).

As capacidades matemáticas envolvem "[...] a capacidade de generalizar objetos, relações e operações matemáticas" (KRUTIETAKI, 1986, p.199, tradução nossa). Uma das atividades realizadas que envolve a contagem dos números e a adição foi a amarelinha, feita de taquara, em que a professora a colocou na frente da sala e as crianças iam pulando e falando o número correspondente.

O professor precisa recorrer a materiais visuais para a formação de conceito, caso contrário será apenas uma assimilação formal das noções, porém 
[...] a etapa de utilização de material concreto não deve prolongarse demasiado. O professor deverá apenas consolidar a experiência imediata dos alunos antes de os guiar, através da abstracção, até à generalização, caso contrário, dar-se-á um atraso na generalização [...] (KALMYKOVA, 1977, p.12-13).

O registro dos numerais está presente na rotina escolar da educação infantil indígena como forma de sistematizar a sequência numérica e a quantificação. Uma das funções dos números é a quantificação, assim, compreender para que servem os números envolve pensar sobre suas funções: “[...] quando se conta ou se quantifica algo, como o número de hectares ou de quilômetros quadrados da área ou terra indígena, reconhece-se que os números têm funções e trabalha-se com um de seus significados - a quantificação" (RCNEI, 1998, p.167).

Para o PPC (2016), o reconhecimento dos números de 01 ao 09 e o ensino relacionando a quantidade com o valor representado pode ser feito por meio da marcação diária do calendário com as crianças e recitar os números já marcados no mês, bem como relacionar a idade, quantidade de irmãos, entre outros.

O ensino de Matemática para as crianças indígenas deve partir do que elas já sabem, de suas vivências e experiências. Por exemplo, as crianças Kaingang possuem uma experiência com a Matemática quando estão em contato com o dinheiro, a família incentiva esse contato, pois quando recebem as moedas, elas contam, guardam e querem comprar algo, participando, dessa forma, da economia familiar. Assim, a educação das crianças e adolescentes está associada à economia familiar, pois o processo educativo não acontece somente quando se conversa com as crianças, mas também quando se educa a criança no campo econômico, bem como para o coletivismo, a previsão, o cuidado e o senso de responsabilidade (MAKARENKO, 1981).

Como destaca Mukhina (1996, p.43), “[...] a experiência social é a fonte do desenvolvimento psíquico da criança; é daí, com o adulto como mediador, que a criança recebe o material com que serão construídas as qualidades psíquicas e as propriedades de sua personalidade”.

Assim, a existência social da criança se realiza nas relações mediadas pelos homens, ou seja, “[...] as relações da criança com as pessoas são mediadas pelos 
objetos (alimentação, vestuário, objetos de cuidados, etc.) tanto quanto suas relações com as coisas são mediadas pelas pessoas (o outro lhe apresenta o objeto, confere, o retira etc.)" (MARTINS, 2006, p.30). Neste sentido,

[...] a experiência social é a fonte do desenvolvimento psíquico da criança; é daí, com o adulto como mediador, que a criança recebe o material com que serão construídas as qualidades psíquicas e as propriedades de sua personalidade (MUKHINA, 1995, p.43).

O desenvolvimento do bebê e das crianças maiores está relacionado à cultura, pois, como destaca Vigotski (2009), o desenvolvimento da criança está relacionado à apropriação da cultura, que "[...] implica uma participação ativa da criança na cultura, tornando próprios dela mesma os modos sociais de perceber, sentir, falar, pensar e se relacionar com os outros" (VIGOTSKI, 2009, p.08).

Considerando as vivências das crianças indígenas Kaingang e tomando as contribuições de Vigotski (1998), destacamos que qualquer situação de aprendizado que a criança tem na escola possui uma história prévia. Neste sentido,

[...] as crianças começam a estudar aritmética na escola, mas muito antes elas tiveram alguma experiência com quantidades - tiveram que lidar com operações de divisão, adição, subtração e determinação de tamanho. Consequentemente, as crianças têm a sua própria aritmética pré-escolar, que somente psicólogos míopes podem negar (VIGOTSKI, 1998, p.110).

O aprendizado desenvolve a zona de desenvolvimento proximal, ou seja, desperta diversos processos internos de desenvolvimento, os quais atuam apenas quando a criança se relaciona com outras pessoas em seu ambiente ou com seus companheiros. Esses processos internalizados tornam-se parte das aquisições do desenvolvimento da criança (VIGOTSKI, 1998).

As crianças indígenas possuem uma cultura e vivenciam tudo nas ruas, calçadas e canteiros da cidade e também nem sua aldeia, pois, conforme pressupostos da Teoria Histórico-Cultural, “[...] o que determina diretamente o desenvolvimento do psiquismo da criança é a sua própria vida, o desenvolvimento dos processos reais desta vida, por outras palavras, o desenvolvimento desta atividade, tanto exterior como interior [...]” (LEONTIEV, 2004, p.310). 
Em relação ao desenvolvimento, Vigotski (1931) destaca que é um processo muito complexo, determinado por uma série de indicações. $\mathrm{O}$ desenvolvimento está relacionado a uma mudança de um processo interno e que acontece em certo organismo, é uma unidade, um fato constante do processo de desenvolvimento e a conexão interna entre o estágio anterior de desenvolvimento e as mudanças que ocorreram. Uma criança de oito anos que aprende as operações matemáticas não faz essas operações como um resultado natural de seu desenvolvimento, mas com as mudanças externas, provenientes do meio e que logo serão um processo de desenvolvimento interno.

A experiência cultural não se desenvolve de fora, independentemente do estado da criança no momento do desenvolvimento, mas na própria criança, assimilando as influências externas, as formas de comportamento, de acordo com seu nível de desenvolvimento psíquico. Por exemplo, uma criança que chega à escola e começa a estudar as quatro operações, isso se dá porque o ensino da aritmética é embasado em certa idade da criança, nos diferentes níveis de aprendizagem, isto é, "[...] a simples assimilação de uma nova operação cultural é fragmentada em uma série de ligações, em estágios que são diferentes e interiormente uns dos outros e que são transformados um no outro [...]" (VIGOTSKI, 1931, p.107, tradução nossa).

O desenvolvimento da criança não tem caráter evolutivo, não acontece com mudanças graduais e lentas, mas é revolucionário, com mudanças súbitas e essenciais no desenvolvimento, nas forças motrizes do processo, assim, cada estágio do desenvolvimento modifica ou nega as propriedades do anterior (VIGOTSKI, 1931). Portanto, são as condições concretas de vida que desenvolve o psiquismo da criança. Outrossim, a família indígena exerce esse papel, pois, quando permite o manuseio das cestarias, das fibras e do dinheiro, apresenta o mundo às crianças.

No entanto, temos que considerar essas vivências como um ponto de partida para os conhecimentos matemáticos. Embora as crianças tenham o contato com o dinheiro, com os números, elas ainda não possuem os conhecimentos numéricos e as operações aritméticas, os conceitos matemáticos, como destaca Leontiev (2005). Assim, 
[...] o ensino da aritmética não deve começar, portanto, com a generalização, mas com a formação activa na criança de acções com objectos externos e, paralelamente, com o movimento e o inventário destes. Posteriormente, estas acções externas transformam-se em linguagem (contar em voz alta), abreviam-se e adquirem por fim o carácter de acções internas (contar mentalmente), que se automatizam na forma de simples actos associativos. Todavia, por detrás destes, ocultam-se agora as acções completas sobre objectos, acções anteriormente organizadas por nós. Por isso estas acções podem sempre de novo ser manifestadas exteriormente (LEONTIEV, 2005, p. 102).

Para Lacanallo (2011, p.53),

[...] o pensamento teórico e as funções psicológicas superiores só serão desenvolvidas caso as experiências vivenciadas pelos sujeitos possibilitem esta forma de desenvolvimento, para isso precisam ser organizadas de modo que o sujeito não as reconheça como algo pronto e acabado. Consideramos que na matemática não é diferente.

Não basta ter apenas as noções matemáticas, por exemplo, para a solução de problemas,

[...] é necessário ser capaz de as usar no momento preciso, escolhendo as noções necessárias para a solução de determinado problema. Costuma suceder que um aluno não consiga resolver um problema por não saber mobilizar as noções que possui. A escolha das noções necessárias exige uma especial concentração sobre o texto do problema, ou seja, analisá-lo (KALMYKOVA, 1977, p.20-21).

A capacidade da matemática é possível por meio de aspectos perceptivos, intelectuais e de memória,

[...] caracterizado pelo pensamento generalizado, reduzido e flexível na esfera das relações matemáticas e simbolismo numérico, e também pelo caráter matemático do intelecto. Em termos de teoria associativa, seria assim: capacidades matemáticas são as capacidades para formar, com base no conteúdo matemático, associações generalizadas, reduzidas, flexíveis e conversíveis e também seus sistemas [...] (KRUTIETAKI, 1986, p.197-198 tradução nossa).

Entretanto, essa capacidade só acontecerá “[...] se os conhecimentos forem entendidos e explicados historicamente" como destaca Lacanallo (2011, p.54). 
Assim, a escola da infância deve ser o melhor lugar para a educação das crianças pequenas, com a possibilidade de apropriação das qualidades humanas que devem estimular o enriquecimento máximo de suas vivências (MELLO, 2007), pois "[...] a idade pré-escolar é a vida em que se abre pouco a pouco à criança o mundo da atividade humana que se rodeia" (LEONTIEV, 2004, p.305). Assim, a "[...] infância é o tempo em que criança deve se introduzir na riqueza da cultura humana histórica e socialmente criada, reproduzindo para si qualidades especificamente humanas" (MELLO, 2007, p.90).

Quando a criança Kaingang retorna para a Terra Indígena e para a escola, cabe ao professor considerar essas vivências, elas serão o ponto de partida, pois o ensino por si mesmo não possibilita o aprendizado e desenvolvimento, porém, quando planejado e sistematizado, resulta em um desenvolvimento mental que movimenta diversos outros processos de desenvolvimento, que não aconteceriam de outra maneira. O aprendizado é um ponto imprescindível e "universal do processo de desenvolvimento das funções psicológicas culturalmente organizadas e especialmente humanas" (VIGOTSKI, 1998, p.118).

Conforme Lacanallo (2011, p.54), o papel do professor é refletir sobre o uso dos recursos em sala de aula

[...] muitas vezes, dos recursos em sala de aula com vistas a organizar as experiências e ações externas entendendo que estas com o tempo terão sentido interno essencial à aprendizagem. A formação dos processos intelectuais em matemática não pode fragmentar e separar o externo do interno, já que é essa relação que garante a compreensão dos conceitos. Essa separação seria um equívoco pedagógico, pois devemos articular e integrar ativamente estas ações para que aprendizagem e desenvolvimento de fato ocorram.

Neste sentido, durante o ano escolar é preciso a atenção do professor para a formação dos conceitos matemáticos, bem como “[...] muito cuidado sempre que introduz um novo conceito, em seguida verifica se as crianças o assimilaram e faz exercícios suplementares quando o considera necessário [...]” (KALMYKOVA, 1977, p.17-18).

Dessa forma, é preciso considerar que há muitas matemáticas, reconhecendo que cada sociedade tem uma forma de compreender o mundo e formas específicas 
de contar e quantificar, bem como a Matemática é "[...] necessária para a construção de conhecimentos relacionados às outras áreas do currículo. O estudo da História e da Geografia, do Português e das variadas línguas indígenas, bem como das Ciências, recorrem cada vez mais à Matemática” (BRASIL, 1998, p.159).

Para a educação escolar indígena, o trabalho da "[...] matemática no diaa-dia da escola é essencial transformar situações da vida em suporte para o estudo da matemática" (FERREIRA, 1998, p.106). Assim, a escola deve considerar o processo de ensino e aprendizagem indígena, os conhecimentos culturais e tradicionais, as experiências e vivências nas cidades. Como destaca Paradise (1991), é o conhecimento cultural presente na sala de aula que se manifesta nos comportamentos e atitudes da experiência extracurricular de crianças, elas o partilham com outros membros do mesmo grupo e o relacionam ao seu mundo sociocultural cotidiano.

Os professores devem intensificar essas vivências, pois as crianças estão no início do desenvolvimento e estão formando e aperfeiçoando as funções psicológicas superiores (a percepção, a memória, os sentimentos), como apresenta Leontiev (1987, p. 57-58, tradução nossa):

O período da infância pré-escolar é a formação inicial da personalidade, o período do desenvolvimento dos «motores» pessoais da condução. Nos anos anteriores ao desenvolvimento do nome do menino, se você definir os números primos, estabeleça os números primários e relacione a forma como a nova unidade superior da atividade e, simultaneamente, a unidade superior do objeto: a unidade da personalidade. Apenas a infância pré-escolar é importante porque é o período de formação física dos mecanismos psicológicos da personalidade.

Nesta defesa, não desconsideramos a realidade da escola na Terra Indígena, as condições de trabalho, estrutura física da instituição escolar, o cenário político, econômico e social no qual a escola e os professores estão inseridos. Os professores e a equipe pedagógica buscam ofertar o melhor para seus alunos, mas as condições objetivas da escola são precárias, com falta de materiais e infraestrutura para a educação infantil e os professores (ANDRIOLI, 2019). Lutamos para que essa realidade possa mudar e oportunizar as crianças Kaingang o desenvolvimento psíquico, por meio de intervenções 
pedagógicas, organização do tempo e do espaço, recursos pedagógicos que contemplem a riqueza, grandiosidade das diferentes áreas do conhecimento, como, por exemplo, a Matemática, Arte, a Música e a Literatura Infantil.

\section{Considerações Finais}

No Paraná, os indígenas Kaingang defendem e reafirmam a importância da escola nas Terras Indígenas como um instrumento que possibilita ressignificar suas lutas e sua cultura e apropriar-se dos conhecimentos historicamente acumulados pela humanidade, entendendo melhor o projeto do Estado e podendo obter um melhor desempenho nas alianças e resoluções dos conflitos, principalmente aqueles relacionados à terra e às garantias legais (FAUSTINO, 2006).

Neste sentido, o estudo de Matemática na experiência escolar indígena é imprescindível, pois caracteriza a inserção no modelo econômico ocidental com o domínio dos modos de produção e comercialização, com o manuseio do dinheiro e cálculos (FERREIRA, 1998). Desta forma, a Matemática possibilita o contato entre os diferentes povos e a sociedade envolvente, o contato no cotidiano resulta "do mercantilismo europeu e do sistema capitalista [...]. Essa Matemática, com bases culturais totalmente distintas, deve ser apreendida pelo indígena [...]" (FERREIRA, 1998, p.12).

As crianças indígenas possuem vivências tanto nas aldeias quanto na cidade com a Matemática. Essas vivências serão o ponto de partida, pois devemos ir além dessa realidade, oportunizar a essas crianças o desenvolvimento psíquico, por meio de intervenções pedagógicas, organização do tempo e do espaço, recursos pedagógicos que contemplem a riqueza, grandiosidade das diferentes áreas do conhecimento, como por exemplo, da Matemática, Arte e Literatura Infantil (ANDRIOLI, 2019).

Não estamos desconsiderando a realidade das crianças indígenas que sofrem as mais diversas formas de violência e preconceito com leis que querem usurpar seus territórios e uma sociedade que não valoriza sua cultura. Da mesma forma, a educação infantil não tem um espaço, uma infraestrutura, materiais, recursos que atendam às crianças, mas destacamos a ação desempenhada pelos professores e 
pela equipe pedagógica como mediadores, que planejam o ensino objetivando sistematizar os conhecimentos e que buscam organizar da melhor forma possível o tempo e o espaço das salas de aula (ANDRIOLI, 2019). Entendemos, como destaca Leontiev (2004), que as aptidões e caracteres humanos não são aprendidos pela hereditariedade biológica, mas no decurso da vida por um processo de apropriação da cultura criada pelas gerações precedentes.

Dessa forma, a importância da aprendizagem escolar na formação das qualidades humanas como memória, percepção, atenção e também da atuação dos professores nesse processo, pois a criança nunca está sozinha, as suas relações são mediadas e intermediadas por e com seus pares, assim, sua atividade está sempre inserida no processo de comunicação, “[...] quer esta se efetue sob a sua forma exterior, inicial, de atividade em comum, quer sob a forma de comunicação verbal ou mesmo apenas mental, é a condição necessária e específica do desenvolvimento do homem na sociedade" (LEONTIEV, 2004, p.290).

Neste sentido, a escola não deve reproduzir e perpetuar a pobreza que o homem tem produzido, mas sim oportunizar vivências com as máximas elaborações humanas, com a sistematização dos conhecimentos historicamente acumulados, superando a sociedade capitalista, a alienação e a intolerância, desenvolvendo o pensamento crítico e político, em busca da emancipação humana.

\section{Referências}

ALVARES, M. M. KitokoMaxakali: a criança indígena e os processos deformação, aprendizagem e escolarização. Revista ANTHROPOLÓGICAS, ano 8, vol. 15(1), 2004.

ANDRIOLI, L. R. Presença e significado da escola: estudo sobre a comunidade bilíngue Kaingang de Faxinal no Paraná. 182f. Dissertação (Mestrado em Educação). Universidade Estadual de Maringá. Orientador: Rosangela Célia Faustino. Maringá, 2012.

ANDRIOLI, L. R. A politica de educação infantil indígena e a sustentabilidade das famílias Kaingang: aprendizagens nas aldeias e nas cidades. 271f. Tese em Educação - Universidade Estadual de Maringá. Orientador: Prof. Dr. Rosangela Célia Faustino. Maringá, 2019. 
ANDRIOLI, L. R.; FAUSTINO, R.C . Vivências de crianças indígenas Kaingang na cidade: elementos para a aprendizagem e o desenvolvimento.

HUMANIDADES \& INOVAÇÃO, v. 6, p. 54, 2019.

BRASIL, Ministério da Educação. Constituição da República Federativa do Brasil. Brasília, 1988.

BRASIL, Ministério da Educação. Lei $n^{\circ}$ 9.394, de 20 de dezembro de 1996. Brasília, 1996.

BRASIL. Ministério da Educação e do Desporto. Referencial curricular nacional para as escolas indígenas. Brasília, 1998.

BRASIL. Constituição (1988). Constituição da República Federativa do Brasil: texto constitucional promulgado em 5 de outubro de 1988, com alterações adotadas pelas Emendas Constitucionais n 1/92 a 46/2005 e pelas Emendas Constitucionais de Revisão n 1 a 6/94. Brasília, DF: Senado Federal, 2005.

BRASIL. Censo: educação escolar indígena. Brasília, 2010.

BRASIL. Censo escolar da educação básica 2016: notas estatísticas. Brasília, 2017.

COELHO, R. O Mieib e a educação infantil de crianças indígenas. In: MIEIB. Discutindo políticas de educação infantil e educação escolar indígena, 2006. Disponível em: <http://www.mieib.org.br/pagina.php?menu=biblioteca>. Acesso em 18 set. 2015.

CRUZ, G. A Da. As políticas públicas educacionais: A (in)visibilidade da educação infantil indígena em Dourados - Mato Grosso do Sul. Revista Eventos Pedagógica. Número Regular: Formação de Professores e Desafios da Escola no Século XXI Sinop, v. 7, n. 2 (19. Ed.), p. 783-797, jun./jul. 2016.

FAUSTINO, R. C. Política educacional nos anos de 1990: o multiculturalismo e a interculturalidade na educação escolar indígena. 2006. 330 f. Tese (Doutorado em Educação) - Programa de Pós-Graduação em Educação, Universidade Federal de Santa Catarina, Florianópolis, 2006.

FAUSTINO. R. C. Cultura, diversidade cultural e prática educativa dos professores com a temática indígena. In: RODRIGUES, Elaine; ROSIN, Sheila Maria (Org.). Infância e práticas educativas. Maringá: Eduem, 2007. p. 235-248. FAUSTINO, R. C. Aprendizagem escolar entre os Kaingang no estado do Paraná: questões sobre língua, alfabetização e letramento. Práxis Educativa, Ponta Grossa, v. 5, n. 2, p. 213-219, jul./dez. 2010. Disponível em:

<http://www.revistas2.uepg.br/index.php/praxiseducativa/article/viewArticle/104 6>. Acesso em 30 nov. 2011. 
FAUSTINO, R.C; SILVA, I. R da. A educação escolar indígena no Paraná. In: SEMINÁRIO NACIONAL ESTADO E POLÍTICA SOCIAIS NO BRASIL, 2003, Cascavel. Anais... Cascavel: Unioste, 2003. Disponível em: <http://cacphp.unioeste.br/projetos/gpps/midia/seminario1/trabalhos/Educacao/eixo1/91Educ acaoescolarindigena.pdf>. Acesso em 20 out. 2011.

FERREIRA, M. K. L. Madikauku: os dez dedos das mãos: matemática e povos indígenas no Brasil. Brasília: MEC, 1998.

IBGE - Instituto Brasileiro de Geografia e Estatística. Características gerais dos indigenas: resultados do universo. Rio de Janeiro: IBGE, 2010. Disponível em: <http://ftp.ibge.gov.br/Censos/Censo_Demografico_2010/Caracteristicas_Gerais_d os_Indigenas/pdf/Publicacao_completa.pdf>. Acesso em 10 Jan. 2014.

INEP - Instituto Nacional de Estudos e Pesquisas Educacionais Anísio Teixeira. Estatísticas sobre educação escolar indígena no Brasil. Brasília: Instituto Nacional de Estudos e Pesquisas Educacionais, 2007.

INEP - Instituto Nacional de Estudos e Pesquisas Educacionais Anísio Teixeira Censo da educação básica: 2012: resumo técnico. Brasília: Instituto Nacional de Estudos e Pesquisas Educacionais Anísio Teixeira, 2013.

ISA - INSTITUTO SOCIOAMBIENTAL. Povos indígenas no Brasil. Disponível em: <http://www.socioambiental.org/pib/index.html>. Acesso em abr. 2004.

KALMYKOVA, Z. L. Pressupostos psicológicos para uma melhor aprendizagem da resolução de problemas aritméticos. In: LURIA, A. R.; LEONTIEV, A. N.; VIGOTSKY, L. S. et al. Psicologia e Pedagogia II. Lisboa: Editorial Estampa, 1977. p. 9-26.

KRUPSKAYA, N.K. A construção da pedagogia socialista: escritos selecionados. São Paulo: Expressão Popular, 2017.

KRUTIETAKI, V. A. Algumas características do desenvolvimento do pensamento nos estudantes com pouca capacidade para as matemáticas. In: LURIA, A. R.; LEONTIEV, A. N.; VIGOTSKY, L. S. et al. Psicologia e Pedagogia II. Lisboa: Editorial Estampa, 1977. p. 59-84.

KRUTIETAKI, V. A. Cuestiones generales sobre la estructura de las capacidades matematicas. In: ILIASOV, I. I.; LIAUDIS, V. Y. A. (Org.). Antologia de la psicologia pedagógica y de lasedades. Habana: Editorial Pueblo y Educación, 1986. p. 195-207.

LACANALLO, L. F. O jogo no ensino da matemática: contribuições para o desenvolvimento do pensamento teórico. 218 f. Tese (Doutorado em Educação) Universidade Estadual de Maringá. Orientadora: Prof ${ }^{a}$. Dr ${ }^{\mathrm{a}}$. Nerli Nonato Ribeiro Mori. Maringá, 2011. 
LEONTIEV, A. O Desenvolvimento do psiquismo. São Paulo: Centauro, 2004.

LEONTIEV, A. Os princípios do desenvolvimento mental e o problema do atraso mental. In: LURIA, A. R.; LEONTIEV, A. N.; VIGOTSKY, L. S. et al. Psicologia e Pedagogia: bases psicológicas da aprendizagem e do desenvolvimento. São Paulo: Centauro, 2005.p. 87-105.

LEONTIEV, A. N. Linguagem, Desenvolvimento e Aprendizagem. São Paulo: Ícone, 2006.

LEONTIEV, A. Uma contribuição à teoria do desenvolvimento da psique infantil. In: VIGOTSKI, Lev Semenovichet al. Linguagem, desenvolvimento e aprendizagem. São Paulo: Ícone, 2001.

MACHADO, M.A. Educação infantil: criança Guarani e Kaiowá da reserva indígena de Dourados. 143f. Dissertação (Mestrado em Educação). Universidade Federal da Grande Dourados. Orientadora: Prof. Dra. Maria Beatriz Rocha Ferreira. Dourados, 2016.

MAKARENKO, A. S. Conferências sobre educação infantil. Trad. Maria Aparecida AbelairaVizzotto. São Paulo: Moraes, 1981.

MARTINS, L. M. A brincadeira de papéis sociais e a formação da personalidade. In: ARCE, Alessandra; DUARTE, Newton. Brincadeira de papéis sociais na educação infantil: as contribuições de Vigotski, Leontiev e Elkonin. São Paulo: Xamã, 2006.

MELLO, S. A. Infância e humanização: algumas considerações na perspectiva histórico-cultural. In: PERSPECTIVA, Florianópolis, v. 25, n. 1, 57-82, jan./jun. 2007.

MENEZES, M.C B. A política de educação escolar indígena e o processo de alfabetização em uma comunidade Kaingang no Paraná. 244f. Tese (Doutorado em Educação) -Universidade Estadual de Maringá. Orientadora: Rosangela Celia Faustino. Maringá, 2016.

MIEIB. Discutindo políticas de educação infantil e educação escolar indígena, 2006. Disponível em: <http://www.mieib.org.br/pagina.php?menu=biblioteca>. Acesso em 18 set. 2015.

MUKHINA, V. Psicologia na idade pré-escolar. São Paulo: Martins Fontes,1995.

NASCIMENTO, A. C.; BRAND, A. J.; AGUILERA URQUIZA, A. H. A criança guarani/kaiowá e a questão da educação infantil. Série Estudos, Periódico do Mestrado em Educação da UCDB, Campo Grande, n. 21, p. 11-23, jul/dez. 2006. 
NASCIMENTO, A. C; BRAND, A. J; AGULERA; URQUIZA, A. H. Entender o outro: a criança indígena e a questão da educação infantil. Caxambu: Trabalho Apresentado na $29^{\circ}$ Reunião da ANPED, 2006.

NASCIMENTO, E. COSTA, R. Indígenas e trabalho infantil: da fronteira étnicocultural à perspectiva de uma ação institucional diferenciada no Brasil. Argumenta Journal Law, Jacarezinho - PR, Brasil, n. 23., s/d. p. 129-158

NUNES, A. Brincando de ser Criança: contribuições da etnologia indígena brasileira à antropologia da infância. Lisboa, Portugal: Departamento de Antropologia do ISCTE, 2003. $341 \mathrm{f}$. Tese de doutoramento. Disponível em $<$ http://hdl.handle.net/10071/684>. Acesso em 15 set. 2020.

PARADISE, R. El conocimiento cultural en el aula: niños indígenas y su orientación hacia la observación. Infancia y Aprendizaje, 1991, p. 55; 73-85. DOI: https://doi.org/10.1080/02103702.1991.10822306

\section{PROPOSTA PEDAGÓGICA CURRICULAR DA EDUCAÇÃO INFANTIL- COLÉGIO ESTADUAL INDÍGENA CACIQUE GREGÓRIO KAEKCHOT - EIEFEM. Terra Indígena Ivaí, 2016.}

Proposta pedagógica e currículo em educação infantil: um diagnóstico e a construção de uma metodologia de análise/Ministério da Educação e do Desporto. Secretaria de Educação Fundamental. Departamento da Política de Educação Fundamental. Coordenação-Geral de Educação Infantil. Brasília: MEC/SEF/ DPEF/COEDI, 1996. 114p.

SILVA, A. R da; MOTA, M. L. Educação infantil na educação indígena: pontos e contrapontos. II Simpósio Luso Brasileiro em Estudos da Criança - Pesquisa com crianças: desafios metodológicos. Anais... 2014.

ROSEMBERG, F. Educação infantil e povos indígenas no Brasil: apontamentos para um debate. In: Discutindo políticas de educação infantil, educação escolar indígena: Recife-PE: MIEIB - Movimento Interfóruns de Educação Infantil no Brasil. Centro de Cultura Luiz Freire-CCLF. Edição: Margarida Azevedo, 2005.

ROSSATO, V. L. Educação infantil entre os Kaiowá e Guarani em Mato Grosso do Sul e suas implicações no Ava Reko. Comunicação apresentada no II Seminário Infância Criança Indígena está sendo organizado pela Universidade Federal de São Carlos, 2014. Disponível em: $<\underline{\text { https://infanciaindigena.files.wordpress.com/2014/10/educac3a7ao- }}$ infantil-entre-os-kaiowc3a1-e-guarani-em-mato-grosso-do-sul-e-suas-implicac3a7c3b5esno-ava-reko-veronice-rossato.pdf $>$. Acesso em 08 de out 2015.

TIRIBA, L. Educação Infantil entre os povos Tupinambá de Olivença. $34^{a}$ Reunião Anual da ANPEd. Educação e Justiça Social. Natal, RN: Anped, 2011. Disponível em: $<$ http://www.revistaaleph.com/educacao-infantil-entre-parenteslicoes-da-creche-tupinamba/>. Acesso em 20 jul. 2014. 
TROQUEZ, M. C. C. Educação infantil indigena na legislação e na produção do conhecimento. Horizontes - Revista de Educação, Dourados, MS, v.4, n.7, janeiro a junho 2016.

VIEIRA, D. da S. Crianças indígenas na cidade: a educação infantil no Centro Social Mitangue-Nhiri. X Seminário de Ciências Sociais - Tecendo diálogos sobre a pesquisa social. Universidade Estadual de Maringá - Departamento de Ciências Sociais. Anais..., 2012.

VIGOTSKI, L. S. Obras Escogidas. Comisión editorial para la edición em lengua rusa. Academia de Ciencias Pedagógicas de la URSS, 1931.

VIGOTSKI, L. S. O desenvolvimento psicológico na infância. Rio de Janeiro: Martins Fontes, 1998.

VIGOTSKI, L. Imaginação e criação na infância: ensaio psicológico. São Paulo: Ática, 2009. 